\title{
Excedente en el desarrollo: revisión y nueva conceptualización desde los extractivismos
}

\section{Eduardo Gudynas*}

Resumen. Se discuten algunos conceptos que son frecuentes en los debates sobre extractivismos en particular y desarrollo en general. Sobre la valoración económica se precisan ciertos problemas derivados de la exclusión de otras valoraciones, de las limitaciones en asignar precios, y de las contabilidades distorsionadas. Seguidamente se considera la categoría renta, indicándose algunas ventajas y desventajas en las posturas ricardiana y marxista convencionales. Luego se aborda la idea de excedente según Paul Baran. Todo el recorrido permite llegar a una redefinición del excedente como una categoría plural, que contiene tres componentes básicos (social, ambiental enfocado en recursos naturales renovables y ambiental referido a recursos naturales no renovables), con algunos aspectos cuantificables en una métrica monetarizada y otros no. Por ello, esta categoría es útil para un análisis desde la economía política y la ecología política.

Palabras clave: excedente, plusvalía, excedente económico, renta, extractivismos.

* Centro Latinoamericano de Ecología Social (Claes), Montevideo, Uruguay. Investigador asociado del Departamento de Antropología de la Universidad de California, en Davis, e investigador visitante del Centro de Estudios Avanzados de la Universidad de Múnich. 


\section{Surplus in development: \\ revision and a new concept after extractivisms}

Abstract. Some features of concepts that are very common in the debates about extractivisms in particular and development in general are discussed. About economic value, limitations derived the exclusion of other values, limitations in assigning prices, and distorted accountabilities are highlighted. Next, the category rent is briefly reviewed, indicating some advantages and disadvantages in the conventional Ricardian and Marxist positions. Then the idea of surplus is addressed following Paul Baran. This results in a redefinition of the surplus as a plural category, which contains three basic components (social, environmental focused on renewable natural resources and environmental referred to non-renewable natural resources), with some quantifiable features in monetarized metrics and others not. Therefore, this category is useful for analysis after political economy and political ecology frameworks.

Keywords: surplus, surplus value, economic surplus, rent, extractivisms. 


\section{Introducción}

En las estrategias de desarrollo que han prevalecido en América Latina, la apropiación y exportación de recursos naturales han desempeñado papeles de enorme relevancia. Tradicionalmente se los ha defendido apelando a los beneficios económicos directos, tales como la llegada de inversiones, aumento de las exportaciones o incremento de la recaudación fiscal, y también indirectos, como la generación de empleo o el acceso a nuevas tecnologías. Ante esos supuestos beneficios se han denunciado perjuicios que también son económicos, junto a otros impactos en las demás dimensiones sociales, territoriales y ambientales.

Buena parte de esas disputas ocurren en una arena economicista, donde se usan argumentos propios de la economía. En sus formulaciones más comunes, los defensores de los extractivismos insisten en que los beneficios económicos superan a las desventajas, y los críticos buscan señalar pérdidas económicas, por ejemplo por contaminación, para insistir en que los perjuicios prevalecerán. En ese tipo de discusiones hay dos términos que son utilizados con mucha frecuencia: renta y excedente. Ejemplos de ellos son las consideraciones sobre la renta petrolera, los gobiernos rentistas, etcétera, como también los señalamientos de excedentes económicos, disputas por excedentes, etcétera. Las dos palabras tienen una larga historia, han sido utilizadas de variadas maneras, y más allá de las desventajas que pudieran tener, también es cierto que ofrecen muchas potencialidades para caracterizar las estrategias de desarrollo.

En el presente artículo se abordan algunas de esas cuestiones. En primer lugar se consideran ciertas limitaciones en las valoraciones económicas para poder así abordar aspectos clave que afectan a la categoría de renta, y 
desde allí se avanza al concepto de excedentes. Se rescatan los aportes de Paul Baran, y siguiendo en parte sus perspectivas, se ofrece una nueva conceptualización de la categoría de excedentes como plural, incluyendo componentes sociales y ambientales de distinto tipo, algunos monetarizables y otros no. El análisis está enfocado en las actividades extractivas (como los sectores minero, petrolero y agropecuario orientados a las exportaciones), y algunas ideas ya fueron adelantadas, por ejemplo, en Gudynas (2015).

\section{Exclusiones y distorsiones en la valoración económica}

Las ideas de renta o excedente económico en los extractivismos presuponen una valoración económica de los recursos naturales, y en ello se encierran un conjunto de problemas que afectan a cualquier entendimiento de esos conceptos. Se puede hablar, por ejemplo, de una renta minera cuando un mineral tiene un valor de mercado.

Esto es parte de un proceso por el cual elementos presentes en la naturaleza, como pueden ser ciertas rocas o determinados suelos, se vuelven útiles para los humanos, son renombrados como recursos naturales, commodities, germoplasma, etcétera, se les asigna valor económico (usualmente representado como un precio), y eventualmente también quedan sujetados a derechos de propiedad. Estas prácticas son muy conocidas, y resultan, por ejemplo, en que a fines de diciembre de 2019, el precio de mercado del mineral de hierro alcanzaba los 91 dólares por tonelada, el grano de soya valía 375 dólares por tonelada, y así sucesivamente.

Bajo estas condiciones ocurren distintos problemas que afectan las interpretaciones de renta y excedente en al menos tres niveles: en la prevalencia 
de la valoración económica que excluye otros valores; en la asignación de precios ya que son incompletos; y en una contabilidad que está distorsionada.

En el primer aspecto, la valoración económica se ha vuelto tan dominante que muchos asumen que es la mejor representación de la esencia del valor de las cosas, y en ellos otros tipos de valores son minimizados o desaparecen, tales como valores culturales, estéticos, religiosos, ecológicos, etcétera. De ese modo, se valora un yacimiento de hierro por la concentración del mineral y se ignoran esos otros valores, como podrían ser la belleza estética del paisaje que está por encima del yacimiento o las funcionalidades ecológicas de los ecosistemas de ese sitio.

Esas limitaciones han recibido múltiples críticas, señaladas especialmente por la economía ecológica, y no es posible repasarlas todas aquí. Pero es necesario tenerlas presentes para poder indicar que ocurren dos procesos simultáneos: hay una valoración económica, y por lo tanto utilitarista, y de base antropocéntrica, que se asume como la mejor representación de un valor esencial, y a la vez se reducen o anulan activamente otras valoraciones. Esto ocurre continuamente con los extractivismos.

El valor económico resultante, expresado en un precio, a su vez enfrenta otros problemas. Siguiendo con el ejemplo del hierro, en la extracción de minerales sólo éste tiene un precio de mercado, mientras que la mayor parte de la materia extraída es considerada desecho sin precio. En la extracción de materia desde la naturaleza la mayor parte es desechada, correspondiendo a las llamadas «mochilas ecológicas», mientras que sólo una fracción es reconvertida en una mercancía transable en el mercado. A esto se suman distintas operaciones que realizan las empresas sobre los precios en los mercados internacionales, actuando sobre los costos de extracción, subsidios, exoneraciones, demanda, oferta, etcétera, que también han sido 
indicadas desde hace años. Todo esto resulta en una valuación incompleta, limitada o manipulada.

Finalmente, le siguen los problemas en la contabilidad. Por ejemplo, al externalizarse los impactos sociales (tales como los efectos sobre la salud pública) o ambientales (como la contaminación del agua), la determinación de costos e ingresos es siempre incompleta. Se despliega una contabilidad por la cual, siguiendo con el caso de los extractivismos, se insiste en que siempre arrojan ganancias pero ello resulta porque una y otra vez se excluyen o no se valorizan los impactos sociales y ambientales, y a su vez la asignación de precios es incompleta, y además se excluyen otras valoraciones. Es una contabilidad distorsionada. Los análisis de costo y beneficio convencionales operan desde esa perspectiva y por ello en la toma de decisiones se persiste con los extractivismos, y los reportes gubernamentales que repiten esos cálculos confirman los beneficios económicos.

Estos tres tipos de problemas y limitaciones están contenidos uno dentro de otro. Desde el punto de vista de los extractivismos en particular, y del desarrollo en general, esto no es una limitación, ni reconocen las distorsiones. Por el contrario, esas manipulaciones son necesarias para mantener la ficción de una alta rentabilidad de los extractivismos. No se está ante acciones ocasionales ni a la falta de pericia, sino a una postura defendida una y otra vez desde los actores que promueven el desarrollo convencional, como empresarios, académicos y políticos. Los extractivismos necesitan ese tipo de contabilidad distorsionada, de las limitaciones en asignar los precios y de la exclusión de otras valoraciones para seguir siendo viables. Este entramado afecta directamente a las concepciones convencionales de la renta y el excedente. 


\section{Renta}

En los usos convencionales actuales del concepto de renta se la presenta como la diferencia entre el valor (en escala monetarizada) del recurso natural en los mercados globales y los costos totales en lo que llaman su «producción», la palabra que usa la economía convencional para referirse a la extracción. Un ejemplo clásico de ese procedimiento son los cálculos de la renta sobre los recursos naturales del Banco Mundial (BM, 2011). Según sus estimaciones más recientes, la renta más alta sobre recursos naturales se registra en la República del Congo (42.7\% del PIB); la más alta en minerales es en Mongolia (28.8\%), en gas natural en Timor Oriental (16.8\%), y para el petróleo en Iraq (37.8\%). Entre los países latinoamericanos, ejemplos de renta del total de recursos naturales es 11.8\% del PIB en Venezuela, 8.9\% en Perú y 3.5\% en Brasil. ${ }^{1}$

Si bien estas y otras concepciones sobre la renta están inmersas en innumerables debates (véase Christophers, 2019a, como ejemplo de uno de los aportes más recientes; una revisión previa todavía relevante en Haila, 1990), a los efectos del presente análisis interesa señalar que están teñidas por todos los problemas explicados en la sección anterior. El precio del recurso extraído está afectado por manipulaciones, exclusiones de valores, y distorsiones en reconocer precios. A su vez, los llamados «costos» también padecen de problemas análogos, tales como las externalidades, ignorar los costos de reposición de patrimonio ecológico dañado, etcétera. De uno y otro lado de la ecuación hay elementos que no son valuados adecuadamente y por lo tanto es una contabilidad distorsionada.

${ }^{1}$ La renta total de recursos naturales es la suma de las rentas en minerales, petróleo, gas natural y forestal; datos para 2017, excepto para Venezuela que datan del 2014, según la base de datos del BM en https://data.worldbank.org; otros aspectos de la metodología en BM (2011). 
De este modo, las discusiones sobre, pongamos por caso, las rentas mineras o petroleras, parten aceptando esas limitaciones y se enfocan en la captura de esa renta, en denunciar a las economías «parásitas», en reclamar tributos más altos sobre la renta capturada por las empresas transnacionales, etcétera. Sin duda esas discusiones son relevantes, pero también deben tenerse presentes sus limitaciones.

Aunque la idea de renta tiene una larga historia, que puede rastrearse hasta Adam Smith, los aportes de David Ricardo no sólo deben ser destacados puesto que abordan cuestiones relevantes para el caso de los extractivismos (especialmente agropecuarios), y explican muchos de los usos contemporáneos como el que se acaba de describir. Ricardo entendía que la «renta de la tierra» correspondía a los pagos de los agricultores al señor o dueño de las tierras para poder utilizarlas (Ricardo, 1945). La renta es el exceso generado por encima del aprovechamiento de tierras de peor calidad, y que el campesino transfiere al propietario. No debe ser confundida, según Ricardo, con un interés o beneficio que pueda arrojar el capital.

Por un lado, Ricardo toma en consideración condiciones clave para la situación actual, tales como enfrentar que la escasez o condiciones ecológicas diferenciales influyen directamente en la renta, pero fiel a las ideas de su siglo, entendía que si bien el suelo era la «fuerza original» de los usos productivos, también sería «indestructible».

El siguiente aporte a destacar en esta sección corresponde a Karl Marx, quien también entiende que existe una renta en la imposición de los dueños de las tierras sobre aquellos que las trabajan, pero considera que ésta es parte de un excedente que se origina allí donde el valor es distinto al precio. Recordemos que en el valor puede ser igual, mayor o menor al precio. Marx distingue tres variedades de renta: las rentas diferenciales tipo I 
y tipo II, y una renta absoluta. ${ }^{2}$ Ninguna de ellas debe ser confundida con una ganancia.

La renta diferencial I se debe a la diferencia de los precios de producción debida, por ejemplo, a suelos de distinta productividad o con diferente acceso a la caminería. La renta diferencial II vuelve complejo el análisis, ya que incorpora otros factores, como el tiempo, el acceso al capital, etcétera. El tercer tipo, la «renta absoluta», responde a las decisiones discrecionales que pueden imponer los propietarios de la tierra, tales como la exclusión de una parcela.

El esquema basado en Marx permite articular la renta como apropiación que hacen los terratenientes sobre capitalistas que cultivan los predios, y éstos últimos, a su vez, obtienen ingresos tanto de los cultivos como de una plusvalía que toman de los asalariados que trabajan en los campos al pagarles bajos sueldos (entendiéndose los términos capitalista y plusvalía en el sentido dado por Marx). En este esquema, los empresarios capitalistas por un lado generan los retornos económicos, y los terratenientes, por otro lado, pasivamente se apropian de parte de sus ingresos. Puede verse que en estas ideas sobre la renta se otorga mucha relevancia a la propiedad o control sobre los recursos, pero también se expanden a considerar las relaciones sociales entre los distintos actores. Estos son componentes que deben ser tenidos en cuenta y son necesarios para entender el desarrollo contemporáneo, pero abordajes como los del Banco Mundial los ignoran. En ese sendero está, por ejemplo, la reciente definición de Christophers (2019b) de considerar a la renta como los ingresos derivados de la propiedad, posesión o control de

\footnotetext{
${ }^{2}$ El asunto es abordado, por ejemplo, en la sección sobre «Cómo se convierte la ganancia extraordinaria en renta del suelo» en el volumen III de El capital (Marx, 2010); para un abordaje reciente véase a Ramírez (2009).
} 
bienes escasos bajo condiciones de competencia limitada o impedida. Pero, de todos modos, sigue faltando la atención a la dimensión ambiental.

Este breve repaso indica que es necesario contar con una categoría que incluya varios de los componentes abordados en las ideas de renta, incorporando con especial atención cuestiones sociales, a tono con Marx, pero que a la vez pueda sumar otras dimensiones que no son consideradas. La categoría de excedentes brinda esa oportunidad.

\section{Excedentes}

El término «excedente» se ha utilizado por décadas en muy diversos análisis políticos y económicos, y en América Latina frecuentemente asociado con los estilos de desarrollo que dependían de exportar materias primas. Un ejemplo destacado de su importancia lo brinda el boliviano René Zavaleta Mercado, quien afirmaba que el control de los excedentes era una cuestión central en las disputas políticas, y éste a su vez, descansaba en una larga historia que comenzaba en la colonia. La minería de Potosí, según Zavaleta Mercado, «decía a gritos que no importa el excedente, sino quién lo capta y para qué» (1984:180), dejando de ser un problema económico para volverse además un «principio transmisor de ideología» (1984:183). A partir de las creencias de una naturaleza latinoamericana que contenía todas las riquezas necesarias, la lucha por controlar esos beneficios se volvieron centrales.

La prevalencia del término excedente no puede sorprender porque su uso puede rastrearse al menos hasta David Ricardo (véase Danielson, 1990a; Lippit, 1999). Con Karl Marx, ocurre una redefinición de la idea que 
ha sido popularizada como plusvalía. Recordemos que se ha utilizado la palabra excedente para el término en inglés surplus, mientras que plusvalía es la traducción preferida para surplus value en inglés o Mehrwert en alemán.

Pero el contenido de este nuevo término es muy distinto. Bajo la concepción de Marx, se lo aplica a un «incremento» o un «exceso» de «valor» en la circulación mercantil por el excedente del trabajo necesario para que los trabajadores puedan subsistir y para mantener los medios de producción. La plusvalía de Marx es la apropiación de parte de los excedentes generados por los trabajadores. ${ }^{3}$

Una nueva etapa en los usos de ese término se debe al economista Paul Baran, ${ }^{4}$ que sigue una perspectiva marxista pero con cambios sustanciales. Baran utiliza el término economic surplus que se ha traducido al castellano como «excedente económico». La ventaja de esa palabra es que deja en claro que es una idea distinta a la de plusvalía.

Baran presentó brevemente el concepto en un artículo corto en 1953, y con más precisión en el libro La economía política del crecimiento, publicado en inglés originalmente en 1957, y en castellano en 1959; en la segunda edición en inglés, en 1962, se agrega un prólogo que ofrece precisiones y respuestas a

${ }^{3}$ Sobre estas cuestiones véase la sección tercera sobre la producción de la plusvalía absoluta en el libro I de El capital (Marx, 2010).

${ }_{4}^{4}$ Paul A. Baran nació en 1909 en Ucrania (en ese momento parte del Imperio de Rusia), educándose inicialmente entre Alemania y Rusia. Al estallar la Segunda Guerra Mundial logró huir de Polonia hacia Estados Unidos, donde volvió a estudiar economía en Harvard. En ese país desempeño distintos trabajos durante la guerra, pero a partir de 1949 tomó un puesto de docente en la Universidad de Stanford, siendo por años el único profesor de tiempo completo marxista en aquel país. Fue un entusiasta viajero y paralelamente desplegó un fuerte apoyo a la revista y editorial Monthly Review. Falleció en 1964. Para más información sobre su obra véase Sweezy, Magdoff y Baran (1971). 
algunas críticas sobre sus ideas (incluido en la segunda edición en castellano en 1975). Tanto el libro y el concepto tuvieron en su momento un fuerte impacto, y se generó un importante debate. El interés aumentó todavía más con El capital monopolista, un libro publicado después del fallecimiento de Baran, conjuntamente con Paul Sweezy (en 1966 en inglés, y en 1968 en castellano).

Baran defiende un concepto ampliado y extendido del excedente económico, entendiéndolo como la diferencia entre la producción real generada por la sociedad y su consumo efectivo corriente. Esto lo hace igual al ahorro y la inversión, e incluye a la idea de plusvalía de Marx, sin suplantarla. Esa ampliación es necesaria a juicio de Baran por varias razones. Entre ellas se cuenta que distintos componentes fueron ocultados o invisibilizados, algunos convertidos en costos para liberarlos del «estigma» de ser calificados como excedentes. El excedente incluiría componentes «visibles» como el ahorro, la renta o el interés, y otros, posiblemente la mayor parte, serían «ocultados» renombrándolos como costos, tal como ocurre por ejemplo con los recursos escasos.

Esa ampliación de la definición permitía incorporar la problemática de lo que en ese tiempo se entendía como subdesarrollo del Tercer Mundo, incluyendo el papel de las empresas transnacionales, la apropiación de materias primas, el gasto estatal, etcétera, todo lo cual no era posible utilizando únicamente la idea de plusvalía (Baran y Sweezy, 1968). Dicho de otro modo, para entender las estrategias de desarrollo era indispensable contar con una categoría de ese tipo.

Es justamente por esa perspectiva que las ideas de Baran sirven como inspiración y tienen potencialidades para organizar un marco de análisis de los modos de apropiación de los recursos naturales y las estrategias de desarrollo actuales. El objetivo aquí no es una revisión exhaustiva de la categoría 
de excedente económico en Baran, sino dejar en claro esas fuentes de inspiración y sus posibles articulaciones con otras perspectivas.

Baran presenta tres tipos de excedentes económicos. Uno real, que como se indicó arriba corresponde a la diferencia entre la producción real generada y el consumo efectivo corriente. Le siguen dos categorías derivadas: excedente económico «potencial» $\mathrm{y}$ «planeado». El excedente económico «potencial» es entendido como la «diferencia entre la producción que 〈podría` obtenerse en un ambiente técnico y natural dado con la ayuda de los recursos productivos utilizables, y lo que podría considerarse como consumo esencial» (Baran, 1975:74). El excedente económico planeado es utilizado para las tareas de planificación en una economía de tipo socialista, lo que era un asunto de relevancia en aquellos años, y apostaba a un uso y un consumo «óptimo» de recursos y bienes.

Baran reconoce que la identificación y medición de esto enfrenta obstáculos e incluso parece admitir sus contornos difusos. La situación se volvió más compleja con el paso de los años, ya que en sus sucesivas obras se agregaban cambios o ajustes, agravando los problemas de interpretación y aplicación. Pero en el manejo de esa dificultad también hay una postura a rescatar. En efecto, Baran confiesa que su idea puede tener algunos «errores» porque no es ni una definición «simple» ni permite una «medición refinada», y una evaluación cuantitativa es lo que le reclamaría la economía convencional en aquellos años (y en la actualidad). Pero Baran responde que su propósito es alejarse de la moda cualitativa y apostar más por abordajes basados en análisis y juicios: «sería deseable romper con la larga tradición del tema a la elegancia del método analítico; es mejor tratar de forma imperfecta lo que es sustancial, que llegar al virtuosismo en el tratamiento de lo que no importa» (Baran, 1975:73). 
En El capital monopolista, Baran y Sweezy brindan una explicación esclarecedora, que a su vez muestra su relevancia ante los extractivismos actuales: «Creemos también que los modos de utilización de los excedentes constituyen el mecanismo indispensable que enlaza los fundamentos económicos de la sociedad con lo que Marx llamó su superestructura política, cultural e ideológica» (1968:12). Enseguida ofrecen un ejemplo de lo que sería una situación donde la apropiación de excedentes es simple y fácilmente analizable:

En una sociedad feudal auténtica, por ejemplo los excedentes son forzosamente extraídos del trabajo de los siervos, por los señores feudales y consumidos directamente por los amos y sus dependientes sin la medicación significativa de comerciantes y otros tipos de intermediarios. Bajo estas circunstancias, los determinantes de la magnitud de los excedentes, la forma en que son usados y la relación entre estas cuestiones y la política y cultura de la sociedad son fácilmente comprensibles. En otras sociedades el mecanismo que conecta los fenómenos económicos y los no económicos es mucho más complicado y puede llegar a tener un papel importante en el funcionamiento de ambos: los fundamentos y la superestructura» (Baran y Sweezy, 1968:12).

Las ideas de Baran, no sólo las de excedente económico, sino la del capital monopolista y sus críticas al capitalismo de su tiempo, tuvieron fuertes repercusiones. En América Latina, sus libros fueron traducidos al español, y algunos de sus textos clave circularon en la influyente serie «Cuadernos de Pasado y Presente» en 1968. Distintos autores han abordado las diferencias y semejanzas entre excedente económico y plusvalía (por ejemplo en Barclay y Stengel, 1975; Szlajfer, 1983; Lippit, 1985), se ha cuestionado que sus ideas se alejaran de un Marx clásico (Santarcángelo y Borroni, 2012), y hay quienes, 
siguiendo esa inspiración, ofrecieron ajustes o nuevas definiciones (por ejemplo, Lippit, 1985; Stanfield, 1974; y Danielson, 1990a, 1990b).

Sin embargo, esas propuestas con el paso de los años quedaron relegadas, y en ello hay una cierta injusticia, especialmente desde una perspectiva latinoamericana. Es que Baran insistía en que los países que eran etiquetados como subdesarrollados en esos años, disponían de importantes excedentes, y señalaba que éstos eran usados por ejemplo en mantener a militares, en el consumo dispendioso de clases dominantes o enviado al exterior como ganancias de las empresas transnacionales, y todo ello impedía condiciones para avanzar en el desarrollo (véase Bona, 2016, para una actualización sobre algunas de estas cuestiones). Ese tipo de análisis tuvieron una influencia importante en abordar las relaciones entre desarrollo y subdesarrollo (Lippit, 1985; Danielson, 1990b), y a su vez, incidieron en la generación del dependentismo latinoamericano. Del mismo modo, aportes como los de capitalismo monopólico que descansa en las grandes corporaciones, tiene resonancias con los extractivismos actuales transnacionalizados. Aunque usan el término «monopolio», Baran y Sweezy (1968:11) admiten que incluyen al caso «más común» de oligopolio, y precisamente algunos sectores extractivistas dependen de oligopolios globales que organizar por un lado la extracción y por el otro la comercialización en los mercados internacionales (Gudynas, 2015).

\section{Excedente como una categoría plural}

Al considerar la situación actual de los extractivismos en particular, y del desarrollo en general, es valioso rescatar la perspectiva de Baran sobre los 
excedentes para avanzar hacia una nueva formulación. No se plantea aplicar exactamente la misma definición sino, por un lado, rescatar algunos de sus componentes positivos, y por el otro, seguir inspirándose en la perspectiva y la intencionalidad de Baran. Del mismo modo, es necesario integrar otros componentes, como los aportes de Marx a las dimensiones sociales al tratar la renta.

Un análisis riguroso muestra que existen «excesos» económicos, pero no pueden ser analizados únicamente desde la economía convencional, ya que tienen orígenes y consecuencias que no pueden ser valuadas adecuadamente, pero que tienen consecuencias económicas. Del mismo modo, esa dinámica discurre en dimensiones sociales, tales como los arreglos políticos que determinan quiénes y cómo se apropian o son perjudicados por los excedentes. Pero también deben integrarse consideraciones ambientales, más allá que existió un intento en ese sentido (Khan y Lippit, 1993).5 Finalmente, debe aceptarse que buena parte de esos excedentes no tienen una expresión monetarizada pero tienen consecuencias económicas.

Es así que en este artículo se presenta una reconceptualización del excedente como una categoría plural que contiene tres componentes básicos: a) social, b) ambiental enfocado en recursos renovables y c) ambiental asociado a recursos no renovables. Este posee algunos aspectos que se pueden cuantificar en una métrica monetarizada pero en otros ello no es posible.

El componente social corresponde a la apropiación del trabajo y tiempo de las personas, utilizando vías conocidas como las ganancias, intereses

${ }^{5}$ Khan y Lippit (1993) propusieron un excedente ajustado ambientalmente (environmentally adjusted surplus), que atiende algunas cuestiones ambientales aunque asociado a un concepto de excedente que no sigue exactamente a Baran. Es una propuesta a escala nacional, donde el ingreso nacional es ajustado con las externalidades ambientales (por ejemplo, contaminación) y reconoce la reducción en recursos naturales. 
y plusvalía, pero también sobre su calidad de vida. En el caso de los extractivismos esto sucede, por ejemplo, con los manejos sobre la plusvalía afectando a los salarios de los trabajadores, pero también con las coberturas en salud o seguridad, rebajas impositivas, etcétera. Son situaciones que se observan en empresas mineras que pagan sueldos paupérrimos o en plantaciones agropecuarias que no protegen a sus trabajadores de los agroquímicos que aplican.

El segundo se refiere a los excedentes en la apropiación de recursos naturales renovables. Son condiciones cercanas a los abordajes clásicos de la renta de la tierra donde el propietario, o quien la controla, obliga a un pago por permitir que ésta sea explotada. Aunque se aproxima a la idea de renta diferencial tipo II de Marx, en la actualidad sabemos que la situación es mucho más compleja, ya que inciden aspectos tales como la calidad del suelo, la disponibilidad de agua, los precios en los «mercados de futuro», etcétera. Entre esos componentes también se encuentran aquellos necesarios para recuperar o proteger el ambiente, o funciones de los ecosistemas que son indispensables, como la polinización o los ciclos hidrológicos. Los excedentes se amplían o reducen de acuerdo a cómo se manejan esos componentes. Es así que en muchas prácticas agrícolas extractivistas, como el monocultivo de soya donde las empresas alquilan o se asocian con los propietarios de la tierra, se desatiende la conservación de suelos y aguas para aumentar el excedente monetarizado disponible para el agronegocio.

El tercer componente en el excedente económico se observa en los aprovechamientos de recursos no renovables, como la minería o los hidrocarburos, pero también en la ocupación del espacio geográfico. La distinción clave es que el recurso se agotará tarde o temprano, y por ello el excedente capturado por el capitalista siempre será proporcional a una 
pérdida de patrimonio natural que no puede ser recuperada. Del mismo modo, el espacio ocupado por un enclave minero implica que será imposible utilizarlo con otro propósito, como puede ser la agricultura. La enorme captura de excedentes que ocurre a ese nivel está enmascarada por evaluaciones como las de una «renta petrolera», donde nunca existe una ganancia en sentido estricto porque en realidad siempre es una pérdida neta de patrimonio natural.

Es importante advertir que tanto el segundo como el tercer tipo de excedentes regularmente se pueden superponer con el primer tipo. Por ejemplo, en la economía de una plantación hay apropiación de excedentes del primer tipo a los asalariados junto a aquellos asociados a los del segundo tipo debidos a los manejos del suelo o el agua. De todos modos el componente social es muy distinto del ambiental, y con ello sus implicancias políticas. Es que los trabajadores rurales podrían declararse en huelga para aumentar sus salarios reduciendo el excedente capturado como plusvalía por los dueños de las empresas. Pero los ecosistemas no pueden protestar cuando se aumenta el excedente a costa de su destrucción. Este límite es muy evidente con los actuales extractivismos ya que implican una remoción masiva de recursos naturales con elevados impactos ecológicos.

En los excedentes se engloba la idea de externalidades. Estas nutren a los excedentes, por ejemplo, cuando los que extraen un recurso natural obtiene ventajas económicas externalizando los costos de los impactos que ocasionan. Sin embargo, no todos ellos pueden ser monetarizados o ni siquiera tienen un valor económico. En este punto es importante recordar que Baran reconocía las dificultades en cuantificar su versión del excedente, y por ello enfatizaba la importancia de insistir en una mirada conceptual. En la presente interpretación se sostiene que ese intento de cuantificación total no tiene 
sentido, ya que hay componentes que no pueden ser monetarizados, o que si lo son, esa valuación adolece de muchas imperfecciones. En lugar de esquivar la situación o tratar de solucionarla por medios ineficaces, aquí se la considera como propia de los excedentes.

Por ejemplo, no puede monetarizarse la calidad de vida o la integridad de los ecosistemas. Sí es posible establecer el costo de algunos aspectos, como puede ser el de descontaminar el agua o la atención médica, pero ello no representa ni el valor de la Naturaleza ni de la calidad de vida de las personas. Pero es claro que los extractivismos operan en esas dos dimensiones y desde allí se generan excedentes.

Abordando esta situación pero desde la mirada de la ecología política, la existencia de excedentes incluye siempre componentes que son consecuencia de pérdidas ambientales, que pueden ser difíciles de recuperar (por ejemplo, la erosión de suelos en la agricultura) o irrecuperables (el agotamiento de minerales es un caso). Por ello, se puede señalar que en el momento en que se «crea» un recurso natural como una mercadería con un precio de mercado, en ese mismo acto, ya se generan excedentes que serán objeto de disputa social y política.

Los análisis convencionales de costo-beneficio o de la renta esconden la problemática que se acaba de abordar. Al considerar, pongamos por caso, los costos por valoraciones incompletas y contabilidades distorsionadas, se configura una situación que es análoga a la denuncia de Baran sobre los «costos ocultos». 


\section{EDUARDO GUDYNAS}

\section{Figura 1}

Representación esquemática de los tres tipos de componentes en los excedentes, en sus dimensiones sociales, ambientales en recursos naturales renovables y en recursos no renovables

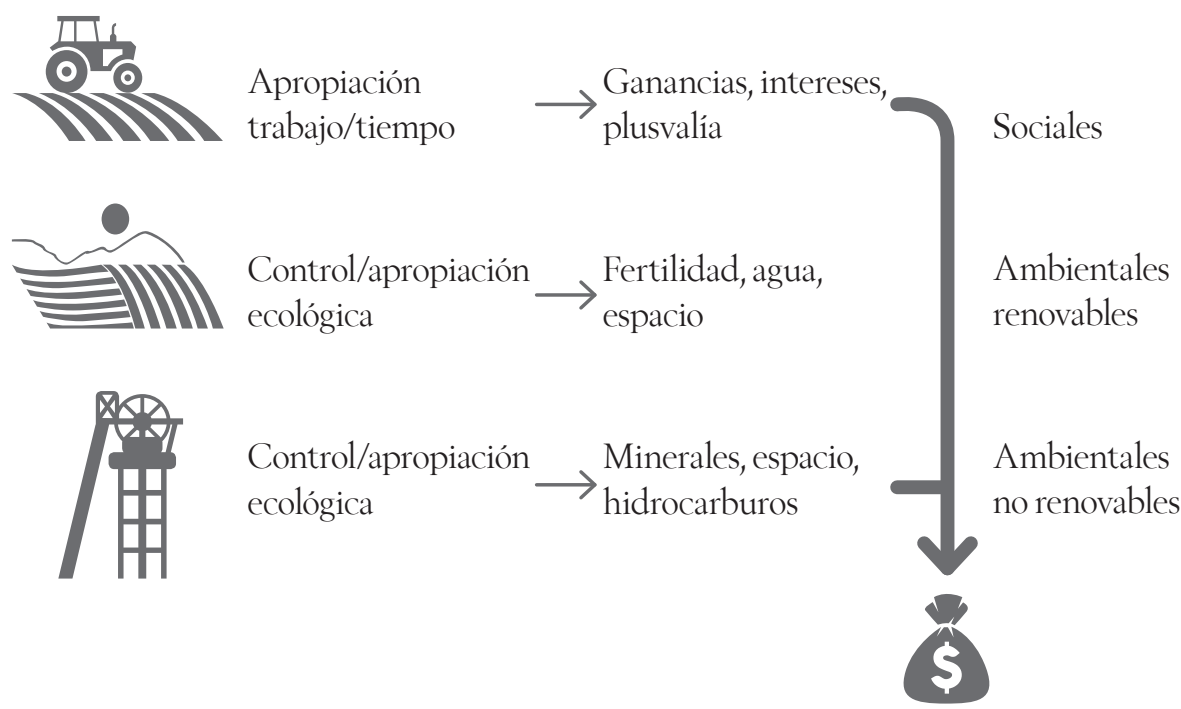

* Se incluyen tan sólo algunos componentes y a manera de ejemplo.

\section{Captura de excedentes, costos y renta}

La reconceptualización de la categoría excedente como plural, incluyendo dimensiones sociales y ambientales, monetarizables y no monetarizables, permite señalar algunas particularidades que ocurren cuando empresas o gobiernos actúan sobre ellos para aumentar sus ganancias. Esto ocurre en los extractivismos, y opera por ejemplo sobre las regalías, los salarios, los gastos en medidas ambientales y sociales, etcétera. 
Las regalías constituyen uno de los instrumentos económicos más conocidos para operar sobre la renta, y de ese modo capturar parte de los excedentes económicos. El instrumento tiene un origen colonial en los pagos que se debían hacer a la corona, y que en la actualidad es ocupado por el Estado. Existen distintos tipos y se aplican según diferentes cálculos (como regalías ad valorem, específicas, basadas en las ganancias o en los precios, etcétera; véase por ejemplo Nakhle, 2010; Hogan y Goldsworthy, 2010).

Aunque en sentido estricto, las regalías son distintas de los impuestos que el Estado impone a personas o empresas, ya que no dependen de los derechos exclusivos sobre los recursos naturales. Pero de todos modos no siempre son fáciles de diferenciar y hay superposiciones. Por ejemplo, en Bolivia, en la administración de Evo Morales, el Estado imponía sobre los hidrocarburos regalías de 18\%, y un impuesto de 32\% (conocido como Impuesto Directo a los Hidrocarburos), alcanzando un total de 50\% (Fundación Jubileo, 2012). Pero por otro lado, Bolivia como otros gobiernos, subsidian a los extractivismos de muy variadas maneras (subvenciones a la exploración y explotación, exoneraciones tributarias, apoyos en infraestructura o energía, etcétera). Incluso se ha llegado a extremos de subordinación en aceptar pagos voluntarios, como ocurrió en Perú con los llamados «óvolos» voluntarios y «solidarios» de compañías mineras (CooperAcción, 2009).

Es evidente que las empresas apuntan a capturar más excedentes por varios modos, desde pagar bajos salarios a evitar pagar impuestos, desde conseguir subsidios a no pagar los costos de los impactos sociales y ambientales. En cualquiera de esos instrumentos no se resuelven los problemas de las limitaciones en asignar precios o la contabilidad distorsionada, indicados arriba, y ello permite generar y apropiarse de excedentes por ejemplo 
operando sobre la externalización de impactos, mientras se exageran gastos e inversiones. En ello se puede apelar a medidas legales, alegales (sacando ventajas de limitaciones en las normas de tributación, control laboral o ambiental), pagando por el lobby ante la clase política, campañas de publicidad, etcétera (muchos de estos componentes eran los que Baran calificaba como economía del despilfarro). Por ejemplo, un estudio para Perú de CooperAcción (2007), mostró que las presiones políticas y empresariales resultaron en que las empresas no pagaron un estimado de 357 millones de dólares en impuestos, y de ellos 37\% eran regalías (entre junio de 2004 y diciembre de 2006).

Recordemos que, como se explicó arriba, en la determinación de costos operan distorsiones de todo tipo, y por ello se terminan afectando las rentas generadas, y con ello los excedentes. Esto es particularmente grave con las externalidades sociales, especialmente sobre la salud pública, y las ambientales. Por ejemplo, son conocidos casos como empresas petroleras que no invierten en asegurar la calidad del agua o agroempresas que no conservan los suelos.

Esas acciones en la dimensión ambiental afectan a lo que podría llamarse como reposición ecológica, apelando a analogías con la idea clásica de los costos de reproducción, tales como un salario que asegura la vida de empleados y obreros, como se adelantó arriba. Así como el empresario puede captar una mayor parte del excedente bajando los salarios de los trabajadores, también puede lograrlo minimizando la reposición ecológica.

Pero la dimensión ecológica tiene una particularidad adicional, ya que en muchos extractivismos no sólo no se paga esa reposición ecológica sino que no es posible. No se puede postular un costo de reposición de minerales o petróleo que sea análogo a cómo puede hacerse en una fábrica con 
los asalariados. Desde una ecología política debe quedar en claro que contamos con recursos finitos, y por lo tanto cada paso en su extracción nos acerca a su agotamiento. Al mismo tiempo, la capacidad de los ecosistemas para amortiguar los impactos ecológicos también es limitada.

Esto es negado por las perspectivas economicistas que promueven a los extractivismos. Como se indicó arriba, esto sucede con las ideas clásicas de renta que no consideran otras dimensiones sociales y ambientales, y las pocas que aceptan, las redefinen como costos. De ese modo, gobiernos y empresas activamente camuflan sus capturas de excedentes aduciendo toda clase de «costos» en explotar minerales o hidrocarburos. Para los extractivismos es necesario ocultar esos otros componentes en juego en los excedentes para que no quede en evidencia que buena parte de esos emprendimientos son en realidad pérdidas netas, irreparables y perpetuas, del patrimonio social y ambiental de cada país.

Esto permite reinterpretar los extractivismos como emprendimientos donde por un lado hay actores que acumulan capital mientras que simultáneamente pierden patrimonio natural. Utilizando el vocabulario convencional de sus propios defensores, se podría sostener que los extractivismos implican una acumulación de capital financiarizado o físico, a la vez que se pierde capital natural y social. Esos dos procesos son inseparables. De un modo análogo, también se puede argumentar que la acumulación de capital en los extractivismos ocurre en tanto el valor económico de los recursos naturales es mayor que el valor del trabajo, físico y en tiempo, de los asalariados, en tanto el precio de esos recursos naturales es menor a sus valores económicos y no-económicos (culturales, religiosos, ecológicos, etcétera). Los precios de los recursos naturales son «baratos» con relación a sus valores, y es precisamente por eso que son explotados. Esos dos procesos también son 
inseparables. Para lograr esto debe anular esas otras caras del valor y distorsionar las contabilidades, tales como se indicó arriba.

El concepto de excedente permite manejar de mejor manera esa problemática y rompe con las limitaciones de la categoría renta. No la excluye, pero pasa a ser un componente dentro de un entramado más amplio y complejo. Por eso mismo, los excedentes no pueden ser valorados únicamente desde una métrica en dinero, en tanto las valoraciones económicas son sólo indicadores parciales frente a la sociedad y el ambiente. Esto permite reubicar a los debates sobre regalías o tributos en otra perspectiva, ya que esas pueden ser batallas muy intensas, pero de todas maneras dependen de una apropiación intensiva de los recursos naturales. Reflejan disputas entre algunos excedentes que se visibilizan como dinero, excluyendo otros costos que podrían contabilizarse y otras valoraciones que no son traducibles económicamente pero afectan el desempeño económico.

En este mismo sentido, aunque todavía acoplado al concepto de renta, apunta el ejercicio de Andreucci y colaboradores (2017), de «acaparamiento de valor» (value grabbing), para sostener que la asignación de derechos de propiedad no responde exclusivamente a la obtención de bienes, sino que opera en movilizar y extraer valor por medio de relaciones rentísticas.

\section{Las disputas sobre los excedentes}

Las disputas sobre los excedentes discurren, por un lado, de forma explícita, como pueden ser las enfocadas en las tradicionales discusiones sobre la renta minera o petrolera, o el papel del Estado en capturarla. Pero por otro lado, la reinterpretación de la categoría de excedente permite reconocer 
que las disputas sobre éste se encuentran implícitas en varios procesos. Por ejemplo, muchos conflictos sociales alrededor de los extractivismos en realidad son batallas sobre los excedentes. Hay actores que desean capturar una mayor proporción de los componentes económicos de los excedentes extractivistas, evitan repetidamente asumir los componentes no monetarizables o bien impiden que sean monetarizados. Del otro lado, están quienes resisten padecer los perjuicios y pérdidas, tanto los que son monetarizables como los que no lo pueden ser. Pero de uno y otro lado no se discute la esencia de la apropiación extractivista, sino que la batalla está enfocada en quienes aprovecharán sus supuestas ventajas.

Las disputas por los excedentes pueden involucrar diversos actores. Por ejemplo, en el caso petrolero se cuenta a las empresas que resisten los pagos, frente a pretensiones de obtener regalías de los gobiernos nacionales, los reclamos de gobiernos locales, e incluso comunidades locales que desean beneficios directos. En algunas circunstancias el conflicto se puede generalizar como ocurrió en Argentina cuando el gobierno de Cristina F. de Kirchner intentó en 2008 aumentar los impuestos a las exportaciones de granos. Ese tipo de captura de excedentes se aplicaba a las corporaciones exportadoras, las que a su vez lo trasladaron a los agricultores, y éstos se rebelaron (Barsky y Dávila, 2008). La protesta rural incluyó a grandes y pequeños agricultores, a organizaciones del campo muy conservadoras y otras progresistas, tuvo amplios respaldos y fue tan intensa que el parlamento anuló la medida. Todos estos casos muestran que el Estado cumple funciones clave en el manejo de los excedentes, no sólo tolerándolos, sino actuando en quienes se benefician o perjudican. Es más, Zavaleta Mercado sostiene que el Estado capitalista teje su historia en la producción, distribución y aplicación del excedente. 
Estos ejemplos muestran que las peleas sobre los extractivismos ya no se centran en buscar alternativas a ese tipo de apropiación de recursos naturales, sino que se discute quiénes y cómo podrán capturar los excedentes económicos en juego. De forma esquemática, unos consideran que esos excedentes deben ser captados sobre todo por el Estado, y otros aceptan que se deriven a empresas. Pero cuando los debates políticos se centran solamente en esas cuestiones, se dan por legitimados los extractivismos. Estos son atributos clave de los extractivismos contemporáneos y que deben ser tenidos en cuenta para elaborar alternativas.

\section{Desmontar los excedentes es ir más allá del desarrollo}

La reconceptualización de la categoría de excedente que aquí se propone tiene por cometido servir a análisis propios de la economía política, la ecología política y los estudios críticos del desarrollo. No pretende ofrecer un marco para otro tipo de abordajes cuantitativos, ya que reconoce que existen aspectos que no pueden ser expresados en una métrica monetarizada. Tampoco los rechaza, pero admite que siempre serán incompletos.

En cambio, al asumir la pluralidad de los excedentes es posible por un lado, repensar algunas posturas actuales sobre el desarrollo, en especial los extractivismos, y por el otro, contribuir a fortalecer las opciones alternativas. En ese sentido, el concepto sirve para entender que buena parte de las disputas sobre los extractivismos son enfrentamientos alrededor de distintos excedentes, y por ello, las alternativas de cambio no bastan con una traslación de los excedentes entre distintos actores. Es más, si la discusión sólo se centra en la idea de renta, se dejan desatendidos otros componentes de los excedentes. 
El concepto de excedente como categoría plural también permite poner en evidencia los distintos manejos que existen en el reconocimiento de valor, para así no seguir autorestringidos a los valores económicos. Los cambios en el precio, y desde allí, también en la propiedad de los recursos, no resuelven los enfrentamientos por los excedentes ni anulan las externalidades sociales y ambientales.

De este modo, la nueva conceptualización que aquí se sigue deja en claro que los excedentes parten de la asignación de valores a la naturaleza. Es por ello que en el momento en que se «crea» $\mathrm{o}$ «desarrolla» un recurso natural, por ejemplo como mercadería o bien, y recibe un precio de mercado, inmediatamente se están generando excedentes, y éstos serán objeto de disputas sociales y políticas. Bajo la mirada que aquí se ofrece, los excedentes se nutren de la diferencia entre una valoración económica de lo que se etiqueta como recursos, que es menor al conjunto de valoraciones económicas y no-económicas (por ejemplo, culturales o ecológicas). Esto hace que los precios de los recursos naturales se vuelvan baratos en relación con sus posibles valores, y como las contabilidades y valuaciones están distorsionadas, eso desemboca en una explotación continuada.

Las personas pueden disputar los beneficios y perjuicios en esos excedentes, pero ello no es posible para los componentes ambientales. La naturaleza no puede sublevarse contra el agotamiento de los recursos o la acumulación de externalidades. Esta pluralidad de los excedentes incide en la dinámica de los conflictos locales, y a la vez afectan las opciones sobre el desarrollo.

Esas condiciones tienen una larga historia en América Latina, y una vez más es apropiado regresar a las advertencias de René Zavaleta Mercado. Agudamente observó que en lugar de discutir sobre las esencias de 
las estrategias de desarrollo, los enfrentamientos buscaban obtener los beneficios de los excedentes, pero no cuestionaban cómo se originaban. En los extractivismos contemporáneos eso ocurre una y otra vez, ya que no siempre se critica la esencia de ese tipo de emprendimientos, sino que la pelea está en quiénes y cómo obtendrán los mayores beneficios.

Siguiendo con las precisiones de arriba, la solución a los impactos de los extractivismos no está en cambiar los actores beneficiados o perjudicados, sino en desmontar sus impactos y externalidades. Sin embargo, la pelea por los excedentes es la que prevalece, y eso explica muchas paradojas que sobre todo han afectado a los progresismos latinoamericanos a inicios del siglo XXI.

Regresando, una vez más a Zavaleta Mercado, se diseminaron políticas conservadoras que usaban cambios en los excedentes por medio de prebendas y gratificaciones, que convertían la «furia del oprimido en una parte del programa del opresor» (Zavaleta, 1984). Esta es una de las razones por las cuales la ideología se transmite con los excedentes. En cambio, para atacar estos problemas en los extractivismos y otras expresiones del desarrollo contemporáneo, las alternativas reales no están en administrar excedentes sino en anularlos.

\section{Referencias}

Andreucci, Diego, Melissa García Lamarca, Jonah Wedekind y Erik Swyngedouw (2017), «Value grabbing:: a political ecology of rent», Capitalism Nature Socialism, 28(3), pp. 28-47.

Banco Mundial (BM) (2011), The changing wealth of nations. Measuring sustainable development in the new millennium, Washington, IBRD World Bank. 
Baran, Paul (1953), «Economic progress and economic surplus», Science and Society, 17, pp. 289-317.

(1957), The political economy of growth, New York, Monthly Review Press.

(1975), La economía política del crecimiento, México, Fondo de Cultura Económica.

(1968), «Excedente económico e irracionalidad capitalista», Cuadernos de Pasado y Presente (3).

Baran, Paul A. y Paul M. Sweezy (1966), Monopoly capital. An essay on the American economic and social order, New York, Monthly Review Press. (1968), El capital monopolista. Ensayo sobre el orden económico y social de Estados Unidos, México, Siglo XXI.

Barclay Jr., William J. y Mitchell Stengel (1975), «Surplus and surplus value», Review Radical Political Economics, 7, pp. 48-64.

Barsky, Osvaldo y Mabel Dávila (2008), La rebelión del campo. Historia del conflicto agrario argentino, Buenos Aires, Sudamericana.

Bona, Leandro M. (2016), «Subdesarrollo y excedente económico: una conexión posible entre los aportes de Paul Baran y Celso Furtado», Cuadernos de Economía Crítica, 4, pp. 95-120.

CooperAcción (2007), Tributación y distribución de las sobreganancias mineras en el Perú, Lima, CooperAcción. (2009), La crisis internacional y sus efectos en la tributación y la contribución social del sector minero, Lima, CooperAcción.

Christophers, Brett (2019a), «The problem of rent», Critical Historial Studies, 6, pp. 303-323.

(2019b), «What is rent?», Dialogues Human Geography, DOI: 10.1177/ 2043820619878060 


\section{EDUARDO GUDYNAS}

Danielson, Anders (1990a), «The economic surplus: formation, distribution and role in economic growth», Social and Economic Studies, 39(1), pp. 127-152.

(1990b), «The concept of surplus and the underdeveloped countries: critique and suggestions», Review Radical Political Economics, 22, pp. 214-230.

Fundación Jubileo (2012) A siete años del IDH ¿en qué gastan los recursos?, La Paz, Fundación Jubileo.

Gudynas, Eduardo (2015), Extractivismos. Ecología, economía y política de un modo de entender el desarrollo y la naturaleza, Cochabamba, Centro de Documentación e Información Bolivia/Centro de Asesoría y Estudios Sociales.

Haila, Anne-Kaarina (1990), «The theory of land rent at the crossroads», Environment and Planning D: Society and Space, 8(3), pp. 275-296.

Hogan, Lindsay y Brenton Goldsworthy (2010), «International mineral taxation. Experience and issues», en Philip Daniel, Michael Keen y Charles McPherson (eds.), The taxation of petroleum and minerals: principles, problems and practice, New York, Routledge/Fondo Monetario Internacional, pp. 122-162.

Khan, Haider A. y Victor D. Lippit (1993), «The surplus approach and the environment», Review Radical Political Economics, 25(3), pp. 122-128.

Lippit, Victor D. (1985), «The concept of the surplus in economic development», Review Radical Political Economics, 17, pp. 1-19. (1999), «Economic surplus», en Philip O’Hara (ed.), Encyclopedia of Political Economy, Londres, Routledge, pp. 251-254.

Marx, Karl (2010). El capital. Crítica de la economía política, México, Fondo Cultura Económica.

Nakhle, Carole (2010), «Petroleum fiscal regimes», enen Philip Daniel, Michael Keen y Charles McPherson (eds.), The taxation of petroleum and minerals: principles, problems and practice, New York, Routledge/Fondo Monetario Internacional, pp. 89-121. 
Ramirez, Miguel D. (2009), «Marx's theory of ground rent: a critical assessment», Contributions to Political Economy, 28(1), pp. 71-91.

Ricardo, David (1945), Principios de economía politica y de tributación, Madrid, Aguilar.

Santarcángelo, Juan E. y Carla Borroni (2012), «El concepto de excedente en la teoría marxista: debates, rupturas y perspectivas», Cuadernos de Economía, 31(56), pp. 1-20.

Stanfield, Ron (1974), «A revision of the economic surplus concept», Review Radical Political Economics, 6, pp. 69-74.

Sweezy, Paul M., Harry Magdoff y Paul A. Baran (1971), Paul A. Baran. El hombre y su obra, México, Siglo XXI.

Szlajfer, Henryk (1983), «Economic surplus and surplus value: an attempt at comparison», Review Radical Political Economics, 15, pp. 107-130.

Zavaleta Mercado, René (2013), «Lo nacional-popular en Bolivia», en Obra completa (tomo II: Ensayos 1975-1984), La Paz, Plural. 
